\title{
The copper-inducible ComR (YcfQ) repressor regulates expression of ComC (YcfR), which affects copper permeability of the outer membrane of Escherichia coli
}

\author{
Mélanie Mermod • David Magnani • \\ Marc Solioz $\cdot$ Jivko V. Stoyanov
}

Received: 10 April 2011/Accepted: 9 July 2011/Published online: 17 November 2011

(C) Springer Science+Business Media, LLC. 2011

\begin{abstract}
The pathway of copper entry into Escherichia coli is still unknown. In an attempt to shed light on this process, a lux-based biosensor was utilized to monitor intracellular copper levels in situ. From a transposon-mutagenized library, strains were selected in which copper entry into cells was reduced, apparent as clones with reduced luminescence when grown in the presence of copper (low-glowers). One low-glower had a transposon insertion in the comR gene, which encodes a TetR-like transcriptional regulator. The mutant strain could be complemented by the $\operatorname{com} R$ gene on a plasmid, restoring luminescence to wildtype levels. ComR did not regulate its own expression, but was required for copper-induction of the neighboring, divergently transcribed $\operatorname{com} C$ gene, as shown by real-time quantitative PCR and with a promoter-lux fusion. The purified ComR regulator bound to the promoter region of the $\operatorname{com} C$ gene in vitro and was
\end{abstract}

Mélanie Mermod and David Magnani have contributed equally to this work

Electronic supplementary material The online version of this article (doi:10.1007/s10534-011-9510-x) contains supplementary material, which is available to authorized users.

M. Mermod · D. Magnani · M. Solioz ( $₫)$.

J. V. Stoyanov

Department of Clinical Pharmacology,

University of Bern, Murtenstrasse 35,

3010 Berne, Switzerland

e-mail: marc@solioz-scientific.ch released by copper. By membrane fractionation, ComC was shown to be localized in the outer membrane. When grown in the presence of copper, $\Delta$ com $C$ cells had higher periplasmic and cytoplasmic copper levels, compared to the wild-type, as assessed by the activation of the periplasmic CusRS sensor and the cytoplasmic CueR sensor, respectively. Thus, ComC is an outer membrane protein which lowers the permeability of the outer membrane to copper. The expression of ComC is controlled by ComR, a novel, TetR-like copper-responsive repressor.

Keywords Copper homeostasis - Outer membrane protein $\cdot$ Copper regulator $\cdot$ Biosensor

\section{Introduction}

Copper is an essential micronutrient for most, if not all, living cells. Its chemical reactivity is based on its high redox potential and cells harness this property by incorporating copper as a cofactor into the active site of enzymes involved in fundamental processes such as energy generation, iron uptake and protection against oxidative stress. Due to its ability to accept and donate electrons, copper can also catalyze unwanted, deleterious reactions, and damage cellular components such as DNA, proteins and membranes. Copper may also catalyze the production of hydrogen peroxide and, in a Fenton type reaction, highly reactive hydroxyl radicals 
can be generated and can oxidize proteins and lipids (Yoshida et al. 1993). Therefore, protective mechanisms against copper have evolved in prokaryotes and eukaryotes. Prokaryotes developed efficient copper resistance mechanisms which involve extracellular, periplasmic, and cytoplasmic sequestration of copper and efficient export. The components of copper homeostasis are tightly regulated by specialized copper-responsive regulators (Nies 2003; Harrison et al. 2000).

A key component of copper homeostasis in Escherichia coli is $\mathrm{CopA}$, the $\mathrm{Cu}(\mathrm{I})$ transporting ATPase of the cytoplasmic membrane. It detoxifies the cytoplasm by extruding excess intracellular copper (Rensing et al. 2000; Rosen and Hellenas 2002). This important pump is induced by copper via the action of CueR, a MerRlike transcription activator, which senses cytoplasmic copper in the zeptomolar range (Rae et al. 1999; Stoyanov et al. 2001; Outten et al. 2000; Petersen and Moller 2000; Changela et al. 2003). CopA pumps copper from the cytoplasm to the periplasmic space. There, a multi-copper oxidase, $\mathrm{CueO}$, and a copper transport system, CusCFBA, safeguard the periplasm against copper toxicity (Franke et al. 2003; Rensing and Grass 2003). CueO, which is also under the control of the CueR regulator, has cuprous oxidase activity and can oxidize $\mathrm{Cu}^{+}$to $\mathrm{Cu}^{2+}$, thus rendering it less toxic (Singh et al. 2004). Enterobactin, a catechol siderophore of E. coli, is very toxic to the cell in the presence of copper. CueO can oxidize enterobactin which, in its oxidized form, sequesters copper and contributes to the detoxification of the periplasm (Grass et al. 2004). The CusCFBA system transports copper from the periplasmic to the extracellular space and is essential in providing copper resistance under anaerobic conditions, presumably because the accessory $\mathrm{CueO}$ copper resistance mechanism cannot operate in the absence of oxygen (Munson et al. 2000; Outten et al. 2001). The cusCFBA operon is induced by copper via the CusRS two-component regulatory system. In contrast to the CueR regulator which responds to cytoplasmic copper, the CusRS system responds to periplasmic copper levels (Outten et al. 2001; Munson et al. 2000). The combined operation of CopA, CueO, CusCFBA, and their respective regulators provide efficient copper homeostasis in E. coli (Nies 2003). While much is known about how copper is being exported and sequestered in E. coli, much less is known about the copper uptake by this organism.
We here addressed the question of copper entry into E. coli by using a lux-based biosensor which responds to cytoplasmic copper levels. The working hypothesis was that cells mutated in copper uptake pathways would have lower cytoplasmic copper levels and could be selected by their reduced luminescence (lowglowers). Thus, low-glowers were selected from a transposon-mutagenized library. One of the lowglowers contained a transposon insertion in the $y c f Q$ regulatory gene; for clarity, we renamed this gene comR (copper outer membrane regulator). ComR is a novel TetR-type copper-inducible repressor which regulates expression of the adjacent, inversely transcribed $y c f R$ gene, which was renamed comC (copperinduced outer membrane component). Com $C$ encodes a 85 amino acid protein which appears to reduce the permeability of the outer membrane to copper. ComR and ComC are thus two novel proteins involved in copper tolerance by E. coli.

\section{Materials and methods}

\section{Generation of transposon library}

Escherichia coli top 10 electrocompetent cells (Invitrogen) were electroporated with a GenePulser (BioRad) at $1.8 \mathrm{kV}$ and a $200 \Omega$ serial resistor with $1 \mu \mathrm{l}$ of EZ:TN $<$ DHFR-1 $>$ transposon (Epicentre Technologies), suspended in $1 \mathrm{ml}$ of SOC medium [2\% trypticase peptone (BBL), $0.5 \%$ yeast extract $(\mathrm{BBL})$, $10 \mathrm{mM} \mathrm{NaCl}, 2.5 \mathrm{mM} \mathrm{KCl}, 10 \mathrm{mM} \mathrm{MgCl} 2,10 \mathrm{mM}$ $\mathrm{MgSO}_{4}, 0.2 \%$ glucose (added after autoclaving)], and incubated for $1 \mathrm{~h}$ at $37^{\circ} \mathrm{C}$ with shaking, followed by plating on LB agar media (Ausubel et al. 1995), supplemented with $10 \mu \mathrm{g} / \mathrm{ml}$ of trimethoprim. Following incubation at $37^{\circ} \mathrm{C}$ for $36 \mathrm{~h}, 8.3 \times 10^{3}$ colonies containing a transposon insert were obtained. The colonies were washed off the plates and aliquots of this transposon library were frozen in $25 \%$ glycerol at $-80^{\circ} \mathrm{C}$.

\section{Mutant selection}

Of the transposon library, electrocompetent cells were prepared and electroporated with the biosensor pUA615 (Stoyanov et al. 2003) as described (Ausubel et al. 1995). Cells were plated on LB plates containing $50 \mu \mathrm{g} / \mathrm{ml}$ of kanamycin and $3 \mathrm{mM}$ of $\mathrm{CuSO}_{4}$. 
After overnight incubation at $37^{\circ} \mathrm{C}$, luminescence of the colonies was recorded with a cooled CCD camera (LAS1000, Fuji). Images were inspected for lowglowers as well as more strongly glowing colonies (high-glowers). Clones of interest were subcloned for further analysis.

Identification of transposon insertion sites

The Wizard Genomic DNA Purification kit (Promega) was used to isolate genomic DNA from $1 \mathrm{ml}$ overnight cultures according to the manufacturer's instructions. PCR was used to generate PCR products spanning the transposon-genome junction by PCR amplification with a single primer, DHFR RP or DHFR FP, complementary to the transposon (see supplementary material, Table S1, for primer sequences). PCR amplifications were conducted with $5 \mathrm{U}$ of LA Taq polymerase (Takara) according to the manufacturer's instructions and the following thermal cycling: $95^{\circ} \mathrm{C}$ for $5 \mathrm{~min}, 60$ cycles of $95^{\circ} \mathrm{C}$ for $30 \mathrm{~s}, 55^{\circ} \mathrm{C}$ for $30 \mathrm{~s}$, and $72^{\circ} \mathrm{C}$ for $3 \mathrm{~min}$, followed by $72^{\circ} \mathrm{C}$ for $5 \mathrm{~min}$. The PCR products were separated on $0.7 \%$ agarose gels and the DNA extracted from the gels, using the Qiagen gel purification kit as described by the manufacturer. The DNA fragments were submitted to a commercial sequencing service (Microsynth, Balgach, Switzerland), using the primers DHFR RP-1 and DHFR FP-1, which were nested relative to the PCR amplification primers.

\section{Cloning of ComR}

A ComR expression vector was constructed by PCR amplification of the comR open reading frame from genomic DNA, using the primers ycfQHisF and ycfQHisR. The resultant PCR product was cut with $X b a I$ and NarI and ligated into the histidine tag expression vector pProExHTa (Invitrogen) to yield an $\mathrm{N}$-terminal $6 \times$ histidine-com $R$ fusion gene containing a cleavage site for rTEV protease for tag removal. The resultant expression vector $\mathrm{pProExComR}$ was verified by sequencing. Cleaved ComR had the N-terminal methionine replaced by gly-ala.

\section{Luminescence assays}

Cultures of $5 \mathrm{ml} \mathrm{LB}$ media were grown aerobically at $37^{\circ} \mathrm{C}$ to an OD at $595 \mathrm{~nm}$ of 0.5 , and induced for $1 \mathrm{~h}$ with $\mathrm{CuSO}_{4}$ as indicated in the experiments.
Luminescence was measure in $0.3 \mathrm{ml}$ aliquots of culture in 96-well microtiter plates with a cooled CCD camera and quantified with the AIDA image analysis software (Raytest).

\section{Purification of ComR}

Histidine-tagged ComR was overexpressed in E. coli by growing cells aerobically to mid-log phase in LB at $37^{\circ} \mathrm{C}$, followed by induction with $5 \mathrm{mM}$ isopropyl- $\beta$ D-thiogalactoside for $2 \mathrm{~h}$. Cells were collected by centrifugation, disrupted with a French press, and the cleared cell lysate applied to a Ni-NTA agarose column (Qiagen). The column was washed with $50 \mathrm{ml}$ of $20 \mathrm{mM}$ imidazole, $50 \mathrm{mM}$ Na-HEPES, pH 7.4, followed by elution of 6His-ComR in $5 \mathrm{ml}$ of $200 \mathrm{mM}$ imidazole in the same buffer. The protein was desalted by dialysis against $50 \mathrm{mM}$ Na-HEPES, pH 7.4. The histidine tag of $1 \mathrm{mg}$ of protein in $1 \mathrm{ml}$ was cleaved with $100 \mathrm{U}$ of rTEV protease (Invitrogen) by incubation for $2 \mathrm{~h}$ at $30^{\circ} \mathrm{C}$ and overnight at $4^{\circ} \mathrm{C}$. The cleaved tag was removed by ultrafiltration on an Amicon ultrafiltration device, using a membrane with a cut-off of $10 \mathrm{kDa}$. One hundredth volume of a protease inhibitor cocktail (100 mM $N$ - $\alpha$-p-tosyl-L-lysine-chloromethyl ketone, $100 \mathrm{mM} N$-p-tosyl-L-phenylalaninechloromethylketone, $100 \mathrm{mM} p$-aminobenzamidine, and $100 \mathrm{mM}$ phenyl-methyl-sulfonyl-fluoride, dissolved in dimethylsulfoxide) was added to the final preparation to prevent degradation.

RNA isolation and cDNA synthesis

Mid-log aerobic cultures in LB media were induced as indicated under Results for $1 \mathrm{~h}$ at $37^{\circ} \mathrm{C}$ and RNA was isolated from $1 \mathrm{ml}$ aliquots, using the Qiagen RNeasy miniprep column kit according to the manufacturer's procedure, including treatment with DNase I (RNasefree) for $1 \mathrm{~h}$ at $37^{\circ} \mathrm{C}$. RNasin $(100 \mathrm{U} /$ sample, Promega) was added and the RNA stored at $-80^{\circ} \mathrm{C}$. The quality of the RNA was checked on $1.2 \%$ agaroseformaldehyde gels. cDNA was transcribed from $1 \mu \mathrm{g}$ of RNA using the iScript cDNA synthesis kit (BioRad) according to the manufacturer's protocol.

Real-time quantitative PCR (qPCR)

Real-time quantitative PCR was performed with the SYBR Premix Ex Taq (Takara) in a LightCycler 1.5 
(Roche). The PCR products were analyzed for specificity and homogeneity by melting curve analysis and electrophoresis on $1 \%$ agarose gels. To normalize the qPCR results, the $E$. coli $16 \mathrm{~S}$ cDNA was amplified with primers $\mathrm{mm} 07$ and $\mathrm{mm} 08$. Reaction conditions were as follows: $95^{\circ} \mathrm{C}$ for $30 \mathrm{~s}, 50$ cycles of $95^{\circ} \mathrm{C}$ for $5 \mathrm{~s}, 58^{\circ} \mathrm{C}$ for $10 \mathrm{~s}$, and $72^{\circ} \mathrm{C}$ for $15 \mathrm{~s}$.

\section{Construction of a $\operatorname{comC}$ promoter-lux fusion}

A $241 \mathrm{bp}$ fragment of the $\operatorname{com} C$ promoter region was amplified by PCR with the primers PycfQF and PycfQR, phosphorylated with polynucleotide kinase, and ligated into pUCD615 (Rogowsky et al. 1987), which had been cut with EcoRI and BamHI, made blunt-ended with Klenow DNA polymerase (Roche), and dephosphorylated with alkaline phosphatase (New England Biolab). The resulting plasmid, pPcomC-lux, had the $\operatorname{com} C$ promoter region cloned in front of the lux gene cluster of Aliivibrio fischeri.

Electrophoretic mobility-shift assays (EMSA)

PCR products of the $\operatorname{com} R-\operatorname{com} C$ intergenic region were amplified from $E$. coli genomic DNA using LA Taq polymerase (Takara) and the primers F1, F2, F3, F4, R1, R2, R3, and R4. EMSA were performed according to Parkhill et al. (1993). Briefly, DNA and purified ComR were incubated in $10 \mathrm{mM}$ Tris, $\mathrm{pH}$ 8.0, $100 \mathrm{mM}$ K-glutamate, $0.1 \mathrm{mM}$ EDTA, $1 \mathrm{mM} \mathrm{CaCl}_{2}$, $5 \%$ glycerol, $1 \mathrm{mM} \mathrm{DTT}, 100 \mu \mathrm{g} / \mathrm{ml} \mathrm{BSA}$, for $15 \mathrm{~min}$ at $20^{\circ} \mathrm{C}$ and then applied to $8 \%$ vertical polyacrylamide gels in $40 \mathrm{mM}$ Tris-acetate, $\mathrm{pH} 8,1 \mathrm{mM}$ EDTA, pre-run at $150 \mathrm{~V}$ for $30 \mathrm{~min}$ at $25^{\circ} \mathrm{C}$. Where required, the following metal salts were added to the incubations: $\mathrm{CuSO}_{4}, \mathrm{AgNO}_{3}, \mathrm{AuCl}_{3}, \mathrm{CoCl}_{2}, \mathrm{CdSO}_{4}$, and $\mathrm{NiSO}_{4}$; note that the added $\mathrm{Cu}^{2+}$ was reduced to $\mathrm{Cu}^{+}$by the DTT in the reaction. Gels were stained with SYBR Green I (Invitrogen) according to manufacturer's protocol and images recorded with a CCD camera under UV light.

\section{Gene knockouts}

The $\operatorname{com} C$ gene was inactivated by using the commercial Targetron gene knockout system (Sigma Aldrich) according to the manufacturer's instructions. Targeted disruption was verified by PCR amplification and sequencing of the corresponding genomic region.
A transposon insertion mutant of $\operatorname{com} C$ was also obtained from NBRP, Japan (strain JD27538).

Localization of ComC

A C-terminal comC-V5-6His fusion was generated by PCR amplification of genomic E. coli DNA with primer ms100 and ms101. The PCR product was ligated into pET101 with the D-Topo kit from Invitrogen according to the manufacturer's instructions, resulting in pETR103. The plasmid was verified by sequencing and transformed into $E$. coli BL21(DE3)RIL (Invitrogen) as described before. Cells were grown aerobically at $37^{\circ} \mathrm{C}$ in $400 \mathrm{ml}$ of LB media to mid-log phase and induced with $1 \mathrm{mM}$ isopropyl- $\beta$-D-thiogalactoside for $2 \mathrm{~h}$. Cells were collected, washed once with $100 \mathrm{mM} \mathrm{NaCl}, 50 \mathrm{mM}$ $\mathrm{NaPi}, \mathrm{pH} 7,4$, and disrupted with a French press at $40 \mathrm{MPa}$. Debris was collected by centrifugation for $10 \mathrm{~min}$ at $8,000 \times g$ and the membranes were pelleted from the supernatant by ultracentrifugation for $1 \mathrm{~h}$ at $100,000 \times g$. Membranes were suspended in $1 \mathrm{ml}$ of $50 \mathrm{mM}$ Na-HEPES, $\mathrm{pH} 7$, and $5 \mathrm{mg}$ fractionated on a 30 to $60 \%$ sucrose gradient as described (Bishop et al. 2000). Inner membrane NADH oxidase was assayed by measuring NADH oxidation at $340 \mathrm{~nm}$ and outer membrane phospholipase A was assayed with a kit from Shizuoka (Japan). ComC-V5-6His was determined by western blotting as described (Towbin et al. 1979), using an anti-histidine-antibody (Qiagen).

\section{Results}

To identify genes involved in copper influx into $E$. coli, we mutagenized cells with a transposon to obtain a random knockout library. This library was transformed with the biosensor pUA615, which consists of the lux operon of A. fischeri under the control of the $E$. coli copA promoter (Stoyanov et al. 2003). As cytoplasmic copper levels rise, the copA promoter, which is under the control of the E. coli CueR regulator, is induced and expression of the downstream lux genes results in luminescence. This allowed in situ monitoring of cytoplasmic copper concentrations by luminescence. The library was screened for low-glowers on solid growth media containing $3 \mathrm{mM}$ copper (Fig. 1a). As proof of concept, we also isolated and analyzed two high-glowers, both of which had a 
A
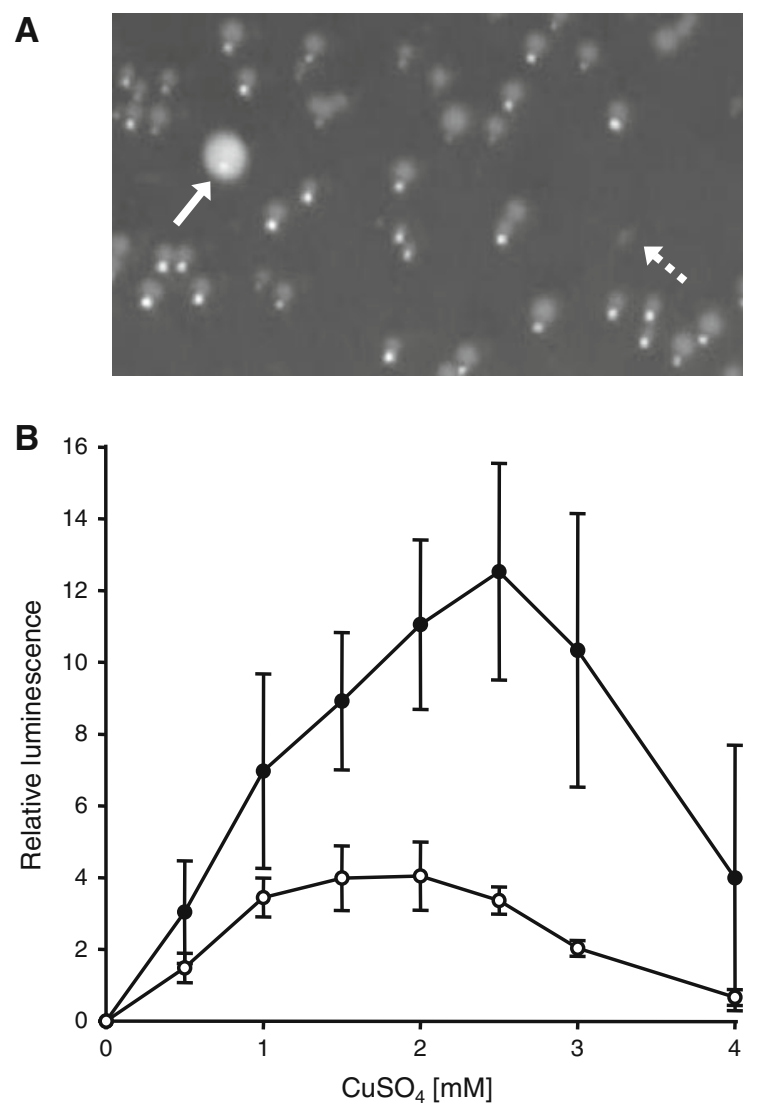

Fig. 1 Detection of cytoplasmic copper with a biosensor. a Transposon-mutagenized cells containing the lux biosensor were plated on $\mathrm{LB}$ agar plates with $3 \mathrm{mM} \mathrm{CuSO}_{4}$ and grown for $14 \mathrm{~h}$ at $37^{\circ} \mathrm{C}$. Luminescence of colonies was recorded with a cooled CCD camera. The bright spots correspond to the bacterial colonies, while the fainter, shadow-like signals are due to light scattered by the agar. The arrow points to a highglower, the dashed arrow to a low-glower colony. b Luminescence was recorded quantitatively in liquid media for the $\Delta$ comR strain (open circle) and the wild-type (closed circle) at different extracellular $\mathrm{CuSO}_{4}$ concentrations. Luminescence was normalized to the number of cells; the error bars indicate the standard deviations of three independent experiments

transposon insertion in the $\operatorname{cop} A$ gene. CopA encodes the only known cytoplasmic copper export pump of $E$. coli and its disruption will of course lead to increased cytoplasmic copper. Several low-glowers were analyzed for the genetic defect. Most of them had transposon insertions in genes which control plasmid copy number, thus reducing the gene-dosage of the biosensor, or were in genes of unknown function. One low-glower of particular interest had a transposon insertion in the comR gene. ComR shares $80-90 \%$ sequence identity with over 100 TetR-like transcriptional regulators in the protein database. However, the activator or ligand is only known for a handful of these (Yu et al. 2010). A TetR-like regulator with a role in copper homeostasis has so far not been identified and the $\operatorname{com} R$ mutant was studied in detail here.

The low-glowing phenotype of the $\Delta$ comR mutant was confirmed in liquid media at different copper concentrations (Fig. 1b). The reduced luminescence of the $\Delta$ comR strain suggested that this mutant contained lower cytoplasmic copper levels compared to the wild-type when exposed to copper. Inspection of the genomic region around the comR gene revealed that it is monocistronic, but is juxtaposed to the divergently transcribed $\operatorname{com} C$ gene. The function of the 85 amino acid protein encoded by $\operatorname{com} C$ is unknown. There is a 241 bp putative promoter region located between $\operatorname{com} R$ and $\operatorname{com} C$. The expression levels of $\operatorname{com} R$ and $\operatorname{com} C$ in response to copper were assessed by qPCR. Expression of $\operatorname{com} R$ was not significantly stimulated by copper (Fig. 2a). In contrast, $\operatorname{com} C$ was induced approximately 30 -fold by $3 \mathrm{mM}$ copper. The expression of $\operatorname{com} C$ was also determined in the comR knockout strain and was found to be increased by 270 -fold on average, supporting the repression of ComC by ComR in the wild-type (Fig. 2b). No significant induction of the nearby upand down-stream genes $n d h, y c f J, y c f M, y d f N$, $y c f O, y c f P, y c f S, y c f T$, and $y c f U$ was observed in the $\triangle \operatorname{comR}$ strain. The $\operatorname{com} C$ gene thus appears to be the only gene of that genomic region which is suppressed by ComR.

To confirm the copper-regulation of the $\operatorname{comC}$ promoter, the $241 \mathrm{bp}$ intergenic region upstream of the comC gene was cloned into a lux reporter plasmid and luminescence was recorded as a function of added copper. Copper induced luminescence maximally 30 -fold at $2 \mathrm{mM}$ copper (Fig. 2c). Induction of luminescence qualitatively agreed with induction of com $C$ mRNA. However, the two assays are expected to respond differently to the toxic effects of copper since the generation of $\operatorname{com} C$ message only requires mRNA synthesis, while induction of luminescence also requires protein synthesis and the generation of substrates for the luminescence reaction. The latter process would be expected to be more susceptible to copper toxicity, which could explain why luminescence decreased above $2 \mathrm{mM}$ copper, while $\operatorname{com} C$ message levels still increased. 

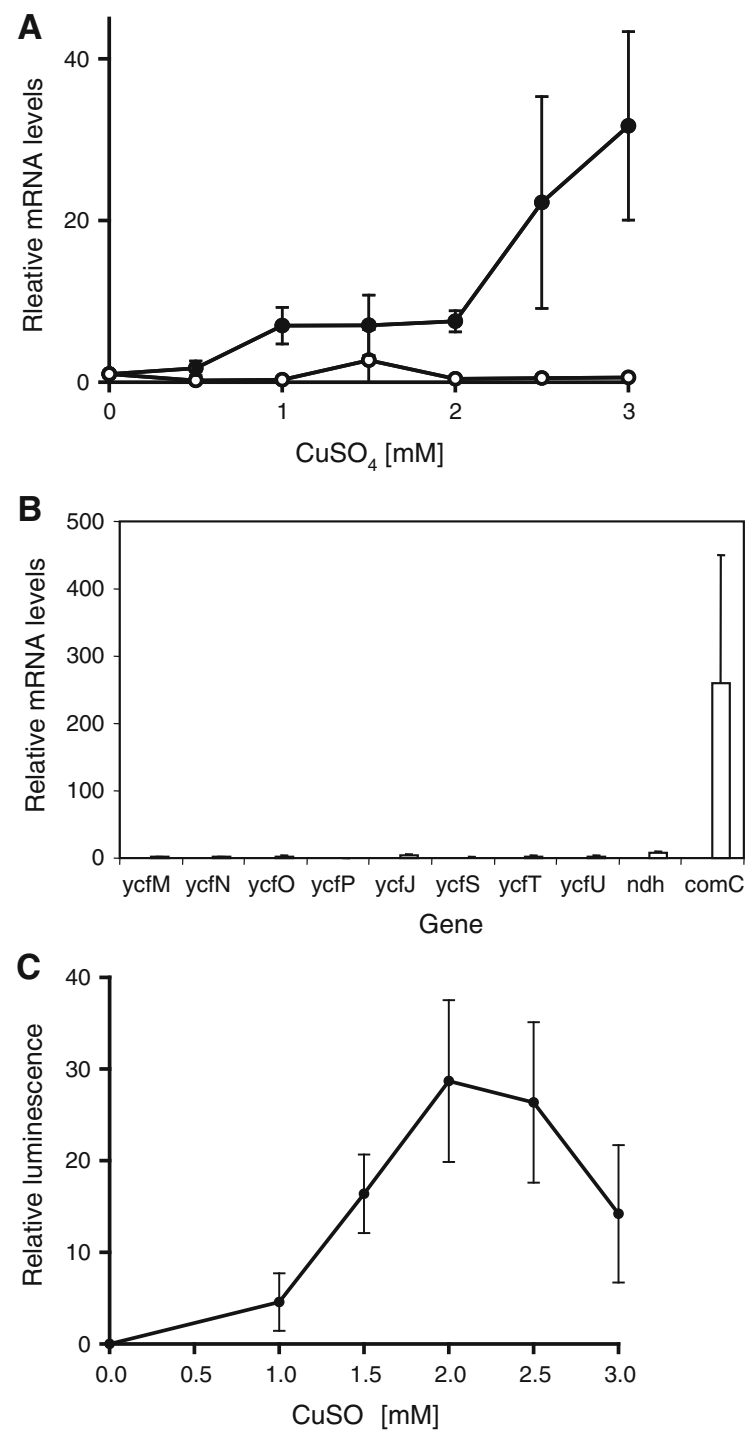

Fig. 2 Induction of comR and comC by copper. a Expression of the comR (open circle) and the comC (closed circle) gene in wild-type $E$. coli, determined by qPCR at a range of $\mathrm{CuSO}_{4}$ concentrations. The error bars indicate the standard deviation of three independent experiments. b Expression of $\operatorname{com} C$ and neighboring genes in the repressor knockout $(\Delta \operatorname{com} R)$. Wildtype and $\Delta$ com $R$ cells were grown until late exponential phase, followed by RNA extraction and qPCR analysis of mRNA levels. Expression levels in the $\Delta$ comR mutant are expressed relative to the wild-type. The error bars show the standard deviations of three independent experiments. $\mathbf{c}$ Induction of a comC promoter-lux reporter by copper. E. coli $\mathrm{DH} 5 \alpha$ containing the reporter plasmid pPcomC-lux was exposed to different $\mathrm{CuSO}_{4}$ concentrations in LB media and the luminescence was measured with a cooled CCD camera and normalized to the number of cells. The error bars indicate the standard deviation of three independent experiments
To test the interaction of the putative ComR repressor with the $\operatorname{com} C$ promoter, ComR was expressed in E. coli as a his-tagged protein, purified to homogeneity, and the his-tag removed by cleavage with rTEV (Fig. 3a). As shown by EMSA, the $241 \mathrm{bp}$ comR-com $C$ intergenic region interacted with purified ComR, with increasing ComR/DNA ratios resulting in increasing complex formation (Fig. 3b). At a molar ComR/DNA ratio of 64, essentially all DNA was shifted to lower mobility. Copper, silver, and gold released ComR from the DNA, but also formed some protein aggregates of intermediate mobility, apparent as dark smears (Fig. 3c). Cobalt, cadmium, and nickel did not dissociate ComR from the DNA. Thus, copper appears to be the physiological inducer of ComR. The binding-region of ComR on the $241 \mathrm{bp}$ fragment used in Fig. 3b, c was narrowed down by testing a set of PCR fragments for the interaction with ComR (Fig. 3d). This delineated an approximately $60 \mathrm{bp}$ region upstream of the $\operatorname{comC}$ gene as the ComR binding-region (Fig. 3e).

Using PSORT (http://psort.nibb.ac.jp/), ComC was predicted to be an outer membrane protein with a 21 or 22 amino acid $\mathrm{N}$-terminal signal sequence. The cellular localization of ComC was determined by expressing a ComC fusion protein with a C-terminal V5-6xHis tag from a plasmid and separating outer and inner membranes from a corresponding culture on a sucrose density gradient (Fig. 4). Phospholipase A and NADH oxidase were assayed to determine outer and inner membrane fractions, respectively. ComC in the fractions was visualized by western blotting, using an anti-histidine antibody. A $12.4 \mathrm{kDa}$ band corresponding to pre-ComC and an $11 \mathrm{kDa}$ band corresponding to processed ComC comigrated with the outer membrane marker, phospholipase $\mathrm{A}$, at the density range 1.23 to $1.26 \mathrm{~g} / \mathrm{ml}$. This experimentally supports the outer membrane localization of ComC, in line with the bioinformatics prediction.

To more directly demonstrate the involvement of ComC in controlling copper leakage of the outer membrane, a knock-out $\Delta c o m C$ strain was analyzed. In line with the working hypothesis, growth of the $\triangle$ com $C$ mutant was more sensitive to copper, compared to the wild-type; the growth rate of the $\Delta \operatorname{com} C$ mutant decreased from approximately $0.5 \mathrm{~h}^{-1}$ without added copper to less than $0.2 \mathrm{~h}^{-1}$ in the presence of $3 \mathrm{mM}$ copper (Fig. 5). In contrast, the growth rate of the wild-type was not significantly affected by copper 
A

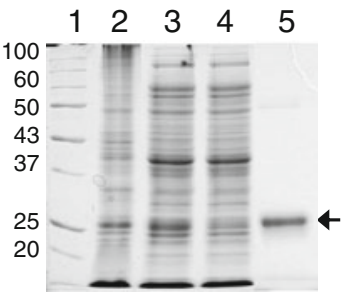

B

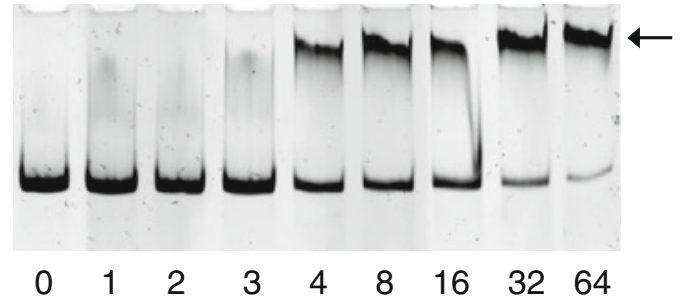

C

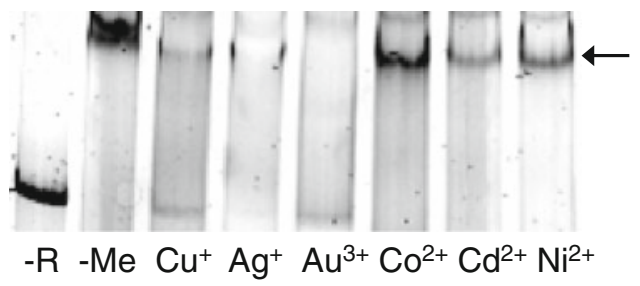

D

Fragment

F1-R1

$\mathrm{F} 1-\mathrm{R} 2$

F1-R3

F1-R4

F2-R1

F3-R1

F3-R2

F3-R3

F4-R1

\section{comR}

$$
\text { (1) }
$$

ComR interaction

E
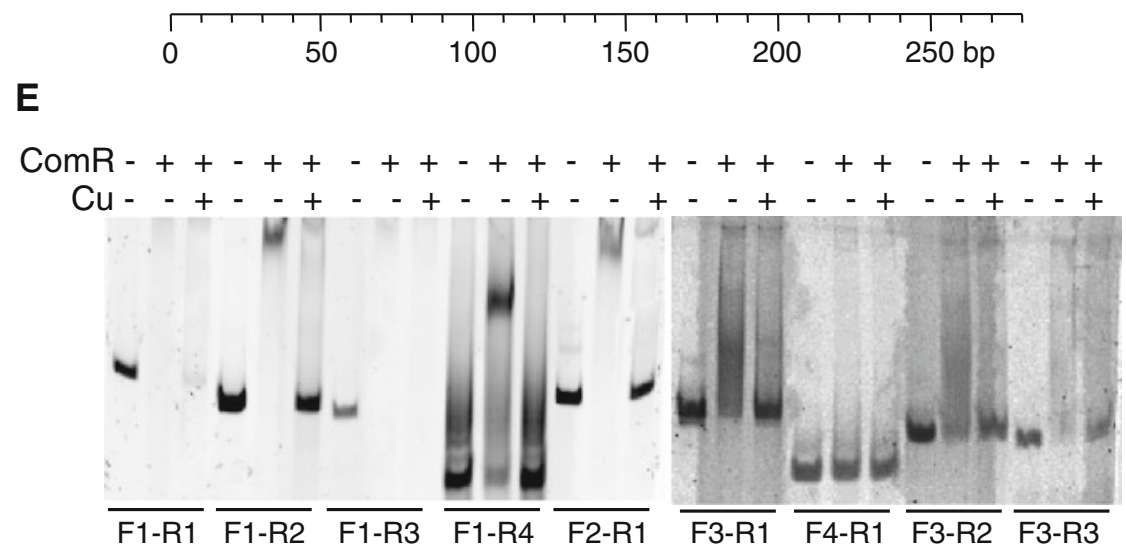

Fig. 3 Interaction of ComR with the $\operatorname{com} C$ promoter. a Coomassie blue-stained SDS gel of the purification of ComR. Lane 1 marker with the molecular weights indicated in $\mathrm{kDa}$; lane 2 cleared lysate of uninduced culture; lane 3 cleared lysate of culture induced for $2 \mathrm{~h}$ with $1 \mathrm{mM}$ isopropyl- $\beta$-D-thiogalactoside; lane 4 flow-through of Ni-NTA column; lane 5 column eluate with $200 \mathrm{mM}$ imidazole. The arrow indicates the migration of recombinant his-ComR. b EMSA with a $241 \mathrm{bp}$ comC promoter fragment $(0.4 \mathrm{pmol})$, which was incubated with purified ComR at the molar ComR/DNA ratios indicated in the Figure, separated by polyacrylamide gel electrophoresis, stained with SYBR green and the gel photographed under UV light. The arrow indicates the protein-DNA complex. c EMSA with the com $C$ promoter fragment without $\operatorname{ComR}(-R)$, or with a 24-fold molar excess of ComR, but no metal $(-\mathrm{Me})$, or with ComR and $50 \mu \mathrm{M}$ of the metal ions indicated below the lanes. Other conditions were as in b. d Intergenic region between $\operatorname{com} R$ and $\operatorname{com} C$, with the starts of these genes indicated by filled arrows. The PCR fragments depicted by bold horizontal lines were generated with the primers listed on the left; the scale at the bottom indicates length in basepairs (bp). Interaction with ComR is indicated by + and - signs on the right of the DNA fragments. e EMSA with the PCR fragments shown in d. DNA fragments $(0.4 \mathrm{pmol})$ were incubated either without ComR $(-)$, a 24-fold molar excess of ComR $(+)$, and without $(-)$ or with (+) $50 \mu \mathrm{M} \mathrm{Cu}^{+}$. Other details of the experiment were as in $\mathbf{b}$ 


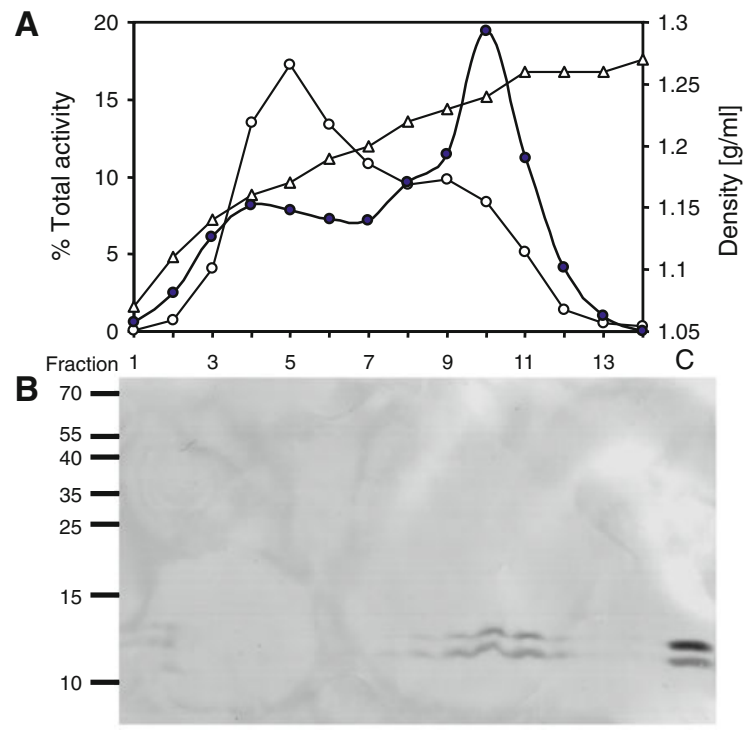

Fig. 4 Membrane localization of ComC. a E. coli membranes were separated on a 30 to $60 \%(\mathrm{w} / \mathrm{v})$ sucrose gradient and fractionated from the top. Fractions were assayed for the inner membrane marker NADH oxidase (open circle) and the outer membrane marker phospholipase A (closed circle), given in $\%$ of total activity. The density (white triangle) is indicated in $\mathrm{g} / \mathrm{ml}$. b Western blot showing the presence of ComC in the fractions of a. The scale on the left indicates the migration of molecular weight markers in $\mathrm{kDa}$. Lane $C 50 \mu \mathrm{g}$ of unfractionated membranes

in this concentration range. In the absence of copper, the wild-type did not grow quite as well as the $\Delta$ comC mutant. While this remains unexplained, it appears clear that the absence of ComC makes cells more copper-sensitive, presumably by making the outer membrane leakier to copper. To assess periplasmic copper levels, we made use of the CusRS regulatory system which naturally senses periplasmic copper and regulates the cusCFBA operon in response to it (Outten et al. 2001; Munson et al. 2000). When the $\triangle$ com $C$ mutant was exposed to copper, expression of the cusCFBA operon was induced over $50 \%$ more strongly than in the wild-type under the same conditions, as assessed by qPCR (Fig. 6a). This supports increased copper leakage across the outer membrane in the $\Delta$ com $C$ mutant. As expected, this in turn also lead to increased cytoplasmic copper, as evident by the increased expression of $\operatorname{cop} A$, which is under the control of the cytoplasmic copper-sensing CueR regulator (Fig. 6b).

Taken together, we here identified ComC as a small, outer membrane protein which reduces the

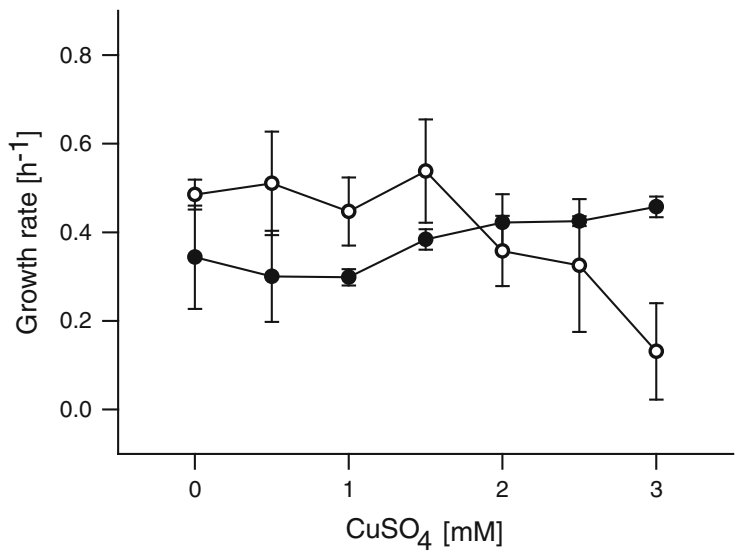

Fig. 5 Effect of copper on the growth rates of wild-type and $\triangle$ com $C$ cells. Cells were grown in LB media, supplemented with different $\mathrm{CuSO}_{4}$ concentrations, and the growth rates were calculated from the logarithmic growth phase of the cultures. closed circle, wild-type; open circle, $\Delta$ comC. The error bars show the standard deviations of three independent experiments

permeability of the outer membrane to copper, probably by reducing leakage. ComC is under the control of the TetR-like repressor ComR. Both, ComC, and ComR are novel proteins involved in the response of E. coli to copper.

\section{Discussion}

Since it is still unknown how copper enters E. coli cells, we here used transposon mutagenesis in combination with a biosensor to identify mutants with altered copper permeability. This led to the identification of a low-glower with a transposon insertion in the $\operatorname{com} R$ transcriptional regulator gene. $\operatorname{ComR}$ is predicted to encode a 210 amino acid protein which belongs to the family of TetR transcriptional regulators. These regulators form a large, diverse group and although over 100 structures are available, only five of these structures (ActR, CgmR, QacR, TtgR, and TetR) are of repressors with proven biological ligand ( $\mathrm{Yu}$ et al. 2010). For most TetR-like repressors, the inducers are still unknown. TetR of E. coli represses transcription by the binding of a homodimer to the promoter (Orth et al. 2000). Upon binding of the inducer, $\mathrm{Mg}^{2+}$-tetracyclin, the protein undergoes a conformational change which lowers its DNA binding affinity and allows transcription to proceed. The structure of ComR could be modeled with SWISS- 

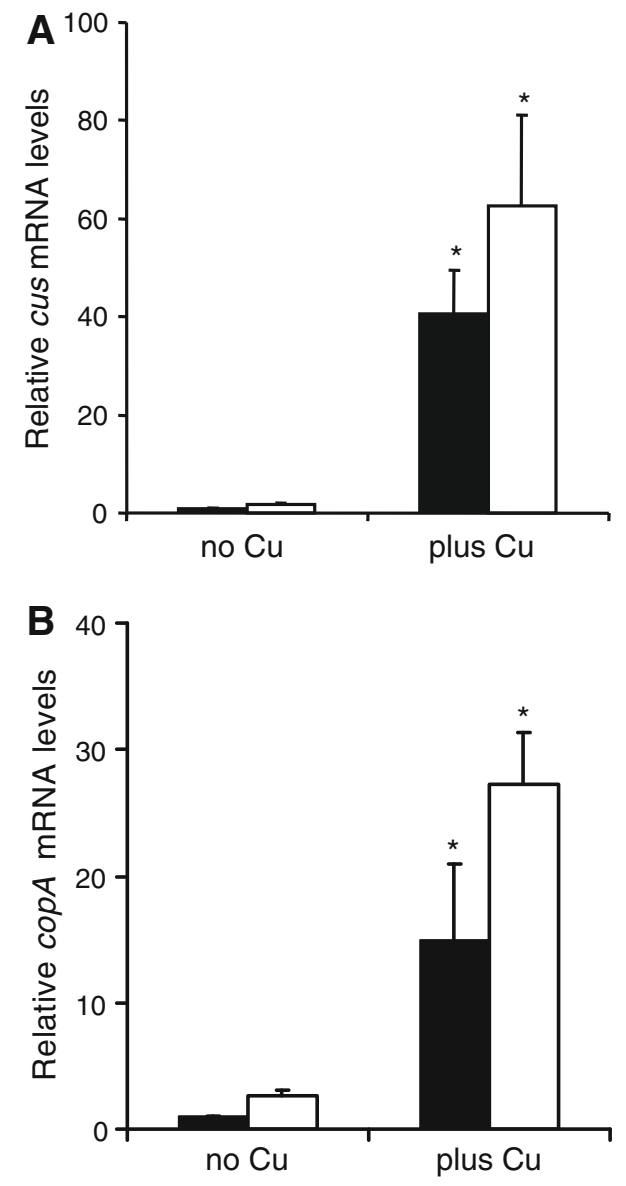

Fig. 6 Induction of copper-regulated genes in wild-type and $\triangle \operatorname{com} C$ cells. Expression of the cus operon (a) and the copA gene (b) was analyzed in wild-type (closed bars) and $\Delta$ comC (open bars) cells in response to copper. Cells were grown to mid-log phase and, where indicated, exposed to $2 \mathrm{mM} \mathrm{CuSO}_{4}$ for $30 \mathrm{~min}$, followed by RNA extraction and qPCR analysis of mRNA levels. Values were normalized to rRNA and expressed relative to wild-type levels in the absence of copper. The error bars show the standard deviations of three independent experiments and the asterisks indicate values significantly different with $P=0.015$ (a) and 0.003 (b)

MODEL, based on the putative TetR regulator from Rhodococcus sp. RHA1 [PDB accession 2I10; (Bordoli et al. 2009)]. This yielded a TetR-like structure for ComR with a potential copper binding site formed by Cys-117, Met-119, and Gln-179 (supplementary Figure S1). Only one other TetR-like metalloregulator has so far been described, namely SczA of Streptococcus pneumoniae (Kloosterman et al. 2007). SczA activates transcription of the $c z c D$ gene, and possibly other genes, in response to $\mathrm{Co}^{2+}, \mathrm{Zn}^{2+}$, or $\mathrm{Ni}^{2+}$. However,
SczA and ComR are evolutionarily distant and share only $17 \%$ sequence identity.

The regulation of the $\operatorname{com} C$ gene by ComR in a copper-dependent manner raised the question of the function of the $9 \mathrm{kDa}$ ComC gene product. A C-terminal V5-6His-fusion of ComC was shown to be localized in the outer membrane, as assessed with an anti-histidine antibody and corresponding inner and outer membrane markers in density gradient-fractionated membranes. Thus, increased levels of ComC in the outer membrane appear to make the membrane less leaky to copper, as apparent by the low-glower phenotype of the comR mutant (constitutive ComC expression) and the increased copper sensitivity of a $\Delta c o m C$ knockout strain. The copper-leak caused by the absence of ComC only allows copper to access the periplasmic space, from where it still has to overcome the permeability barrier of the cytoplasmic membrane to get into the cytoplasm. This, together with the house-keeping function of the CopA ATPase in exporting cytoplasmic copper, could explain the relatively weak copper-sensitive phenotype of a $\Delta c o m C$ strain. Increased periplasmic copper levels in the $\triangle \operatorname{com} C$ mutant could however directly be demonstrated by the increased expression of the cusCFBA copper efflux pump, which is regulated by the periplasmic copper-sensing CusRS regulator.

In various microarray studies, $\operatorname{com} R$ was found to be induced 25 -fold by $25 \mu \mathrm{M}$ cadmium (Egler et al. 2005) (copper was not found to induce $\operatorname{com} C$, but the report relied on a single dataset), during a $\mathrm{pH}$-shift from 8.7 to 5 (Maurer et al. 2005), a heat-shock of $50^{\circ} \mathrm{C}$ for $7 \mathrm{~min}$ (Richmond et al. 1999), treatment with $5 \mathrm{mM}$ sodium salicylate (Pomposiello et al. 2001), and $1 \mathrm{mM}$ hydrogen peroxide (Zheng et al. 2001). More recently, ComC was also reported to be involved in biofilm formation (Zhang et al. 2007). It was found that a $\operatorname{com} C$-deletion rendered cell more hydrophobic, increased cell aggregation, and sensitivity to acid, heat, hydrogen peroxide, and cadmium. It remains unclear to what extent and by what mechanism ComC was involved in all these phenotypic observations.

Based on bioinformatics, the promoter region of comC is predicted to contain a binding site for the cAMP response protein (CRP), which is a global regulator involved in catabolite repression (Brown and Callan 2004). CRP-binding to a 259 bp DNA fragment upstream of $\operatorname{com} C$ was also shown experimentally (Zhang et al. 2007). In addition, comC-induction 
by cadmium was shown to be lower in an rpoE mutant (Egler et al. 2005). RpoE of E. coli functions in general stress response and controls the extracytoplasmic function protein family [proteins involved in maintaining the integrity of periplasmic and outer membrane components (Egler et al. 2005)]. These findings suggested that $\operatorname{com} C$ expression is modulated by the global regulators RpoE and CRP, in addition to the copper-dependent regulation by ComR shown here. However, induction of comC by copper via ComR is much more pronounced than the effects described for RpoE and CRP and we assume that copper-induction of $\operatorname{comC}$ is the principal regulation of this gene. Conceivably, ComC functions as a scaffolding or tethering protein in the outer membrane.

In line with a periplasmic function of ComC, related proteins could not be found in Gram-positive bacteria by a BLAST search, while the genomes of most, if not all, Gram-negative bacteria encode proteins with 50 to $90 \%$ sequence identity to ComC. Thus, ComC-like proteins are a typical feature of outer membranes of Gram-negative organisms. The widespread occurrence of ComC-like proteins contrasts with the lack of information on the localization, structure, and function of this family of proteins and we here present the first study of such a protein.

Acknowledgments We thank Thomas Weber for expert technical assistance and the National BioResource Project (NIG, Japan) for providing strain JD27538. This work was supported by Grant 3100A0_122551 from the Swiss National Foundation and grants from the International Copper Association and the Swiss State Secretary for Education \& Research.

\section{References}

Ausubel RM, Brent R, Kingston RE, Moore DD, Smith JA, Struhl K (1995) Current protocols in molecular biology. John, New York

Bishop RE, Gibbons HS, Guina T, Trent MS, Miller SI, Raetz CR (2000) Transfer of palmitate from phospholipids to lipid $\mathrm{A}$ in outer membranes of gram-negative bacteria. EMBO J 19:5071-5080

Bordoli L, Kiefer F, Arnold K, Benkert P, Battey J, Schwede T (2009) Protein structure homology modeling using SWISS-MODEL workspace. Nat Protoc 4:1-13

Brown CT, Callan CG Jr (2004) Evolutionary comparisons suggest many novel cAMP response protein binding sites in Escherichia coli. Proc Natl Acad Sci USA 101: 2404-2409

Changela A, Chen K, Xue Y, Holschen J, Outten CE, O'Halloran TV, Mondragon A (2003) Molecular basis of metal- ion selectivity and zeptomolar sensitivity by CueR. Science 301:1383-1387

Egler M, Grosse C, Grass G, Nies DH (2005) Role of the extracytoplasmic function protein family sigma factor RpoE in metal resistance of Escherichia coli. J Bacteriol 187:2297-2307

Franke S, Grass G, Rensing C, Nies DH (2003) Molecular analysis of the copper-transporting efflux system CusCFBA of Escherichia coli. J Bacteriol 185:3804-3812

Grass G, Thakali K, Klebba PE, Thieme D, Muller A, Wildner GF, Rensing C (2004) Linkage between catecholate siderophores and the multicopper oxidase $\mathrm{CueO}$ in Escherichia coli. J Bacteriol 186:5826-5833

Harrison MD, Jones CE, Solioz M, Dameron CT (2000) Intracellular copper routing: the role of copper chaperones. Trends Biochem Sci 25:29-32

Kloosterman TG, van der Kooi-Pol MM, Bijlsma JJ, Kuipers OP (2007) The novel transcriptional regulator SczA mediates protection against $\mathrm{Zn}^{2+}$ stress by activation of the $\mathrm{Zn}^{2+}$-resistance gene czcD in Streptococcus pneumoniae. Mol Microbiol 65:1049-1063

Maurer LM, Yohannes E, Bondurant SS, Radmacher M, Slonczewski JL (2005) $\mathrm{pH}$ regulates genes for flagellar motility, catabolism, and oxidative stress in Escherichia coli $\mathrm{K}-12$. J Bacteriol 187:304-319

Munson GP, Lam DL, Outten FW, O'Halloran TV (2000) Identification of a copper-responsive two-component system on the chromosome of Escherichia coli K-12. J Bacteriol 182:5864-5871

Nies DH (2003) Efflux-mediated heavy metal resistance in prokaryotes. FEMS Microbiol Rev 27:313-339

Orth P, Schnappinger D, Hillen W, Saenger W, Hinrichs W (2000) Structural basis of gene regulation by the tetracycline inducible Tet repressor-operator system. Nat Struct Biol 7:215-219

Outten FW, Outten CE, Hale J, O'Halloran TV (2000) Transcriptional activation of an Escherichia coli copper efflux regulon by the chromosomal MerR homologue. CueR J Biol Chem 275:31024-31029

Outten FW, Huffman DL, Hale JA, O'Halloran TV (2001) The independent cue and cus systems confer copper tolerance during aerobic and anaerobic growth in Escherichia coli. J Biol Chem 276:30670-30677

Parkhill J, Ansari AZ, Wright JG, Brown NL, O'Halloran TV (1993) Construction and characterization of a mercuryindependent MerR activator (MerRAC): transcriptional activation in the absence of $\mathrm{Hg}(\mathrm{II})$ is accompanied by DNA distortion. EMBO J 12:413-421

Petersen C, Moller LB (2000) Control of copper homeostasis in Escherichia coli by a P-type ATPase, CopA, and a MerRlike transcriptional activator, CopR. Gene 261:289-298

Pomposiello PJ, Bennik MH, Demple B (2001) Genome-wide transcriptional profiling of the Escherichia coli responses to superoxide stress and sodium salicylate. $\mathrm{J}$ Bacteriol 183:3890-3902

Rae TD, Schmidt PJ, Pufahl RA, Culotta VC, O'Halloran TV (1999) Undetectable intracellular free copper: the requirement of a copper chaperone for superoxide dismutase. Science 284:805-808

Rensing C, Grass G (2003) Escherichia coli mechanisms of copper homeostasis in a changing environment. FEMS Microbiol Rev 27:197-213 
Rensing C, Fan B, Sharma R, Mitra B, Rosen BP (2000) CopA: an Escherichia coli $\mathrm{Cu}(\mathrm{I})$-translocating P-type ATPase. Proc Natl Acad Sci USA 97:652-656

Richmond CS, Glasner JD, Mau R, Jin H, Blattner FR (1999) Genome-wide expression profiling in Escherichia coli K-12. Nucleic Acids Res 27:3821-3835

Rogowsky PM, Close TJ, Chimera JA, Shaw JJ, Kado CI (1987) Regulation of the vir genes of Agrobacterium tumefaciens plasmid pTiC58. J Bacteriol 169:5101-5112

Rosen J, Hellenas KE (2002) Analysis of acrylamide in cooked foods by liquid chromatography tandem mass spectrometry. Analyst 127:880-882

Singh SK, Grass G, Rensing C, Montfort WR (2004) Cuprous oxidase activity of CueO from Escherichia coli. J Bacteriol 186:7815-7817

Stoyanov JV, Hobman JL, Brown NL (2001) CueR (YbbI) of Escherichia coli is a MerR family regulator controlling expression of the copper exporter CopA. Mol Microbiol 39:502-512

Stoyanov JV, Magnani D, Solioz M (2003) Measurement of cytoplasmic copper, silver, and gold with a lux biosensor shows copper and silver, but not gold, efflux by the CopA ATPase of Escherichia coli. FEBS Lett 546:391-394

Towbin H, Staehelin T, Gordon J (1979) Electrophoretic transfer of proteins from polyacrylamide gels to nitrocellulose sheets: procedure and some applications. Proc Natl Acad Sci USA 76:4350-4354

Yoshida Y, Furuta S, Niki E (1993) Effects of metal chelating agents on the oxidation of lipids induced by copper and iron. Biochim Biophys Acta 1210:81-88

Yu Z, Reichheld SE, Savchenko A, Parkinson J, Davidson AR (2010) A comprehensive analysis of structural and sequence conservation in the TetR family transcriptional regulators. J Mol Biol 400:847-864

Zhang XS, Garcia-Contreras R, Wood TK (2007) YcfR (BhsA) influences Escherichia coli biofilm formation through stress response and surface hydrophobicity. J Bacteriol 189:3051-3062

Zheng M, Wang X, Templeton LJ, Smulski DR, LaRossa RA, Storz G (2001) DNA microarray-mediated transcriptional profiling of the Escherichia coli response to hydrogen peroxide. J Bacteriol 183:4562-4570 